Article

\title{
The Plastidial Glyceraldehyde-3-Phosphate Dehydrogenase Is Critical for Abiotic Stress Response in Wheat
}

\author{
Xixi Li, Wenjie Wei, Fangfang Li, Lin Zhang, Xia Deng, Ying Liu * and Shushen Yang * \\ College of Life Sciences, Northwest A\&F University, Yangling 712100, Shaanxi, China; \\ lixixi2018wlf@163.com (X.L.); wenjiewei2011@163.com (W.W.); liffnwafu@163.com (F.L.); \\ Lin798335901@163.com (L.Z.); 18209272902@163.com (X.D.) \\ * Correspondence: yangshushen2014@163.com (S.Y.); yingliu@nwafu.edu.cn (Y.L.); \\ Tel.: +86-135-7257-6526 (S.Y.); +86-180-9257-5284 (Y.L.)
}

Received: 20 January 2019; Accepted: 2 February 2019; Published: 4 March 2019

\begin{abstract}
Plastidial glyceraldehyde-3-phosphate dehydrogenase (GAPDH, GAPCp) are ubiquitous proteins that play pivotal roles in plant metabolism and are involved in stress response. However, the mechanism of GAPCp's function in plant stress resistance process remains unclear. Here we isolated, identified, and characterized the TaGAPCP1 gene from Chinese Spring wheat for further investigation. Subcellular localization assay indicated that the TaGAPCp1 protein was localized in the plastid of tobacco (Nicotiana tobacum) protoplast. In addition, quantitative real-time PCR (qRT-PCR) unraveled that the expression of TaGAPCp1 (GenBank: MF477938.1) was evidently induced by osmotic stress and abscisic acid (ABA). This experiment also screened its interaction protein, cytochrome b6-f complex iron sulfite subunit (Cyt b6f), from the wheat cDNA library using TaGAPCp1 protein as a bait via the yeast two-hybrid system (Y2H) and the interaction between Cyt b6f and TaGAPCp1 was verified by bimolecular fluorescence complementation assay (BiFC). Moreover, $\mathrm{H}_{2} \mathrm{O}_{2}$ could also be used as a signal molecule to participate in the process of Cyt b6f response to abiotic stress. Subsequently, we found that the chlorophyll content in OE-TaGAPCp1 plants was significantly higher than that in wild type (WT) plants. In conclusion, our data revealed that TaGAPCp1 plays an important role in abiotic stress response in wheat and this stress resistance process may be completed by $\mathrm{H}_{2} \mathrm{O}_{2}$-mediated ABA signaling pathway.
\end{abstract}

Keywords: TaGAPCp1; yeast two-hybrid system (Y2H); BiFC; abscisic acid (ABA); hydrogen peroxide $\left(\mathrm{H}_{2} \mathrm{O}_{2}\right)$

\section{Introduction}

Wheat (Triticum aestivum L.) is one of the most important food crops in the world. However, crop yields have fallen sharply due to climate change and widespread drought $[1,2]$. Glyceraldehyde-3-phosphate dehydrogenase (GAPDH) is a key enzyme in the glycolytic pathway [3]. GAPDH was once considered a simple "housekeeping gene". Therefore, it is often used as a reference for gene expression and protein research [4].

However, GAPDH has recently been shown to play a vital role in many cellular processes, like energy production, DNA repair, transcriptional regulation, sugar and amino acid balance, embryo development, viable pollen development, root growth and abscisic acid (ABA) signal transduction $[5,6]$, except for glycolysis [7-9]. Studies have shown that GAPDH is divided into four subfamilies of GAPA/B, GAPC, GAPCp and GAPN in plant cells [10-12], renamed subfamily I, subfamily II, subfamily III and subfamily IV, separately. In Arabidopsis, phosphorylated GAPDH contains two gapA, two gapC and two gap $C p$ genes, with only a single gapB [6,13]. According to previous studies, there were 13 GAPDH 
genes in wheat, including five gapCp genes [14]. GAPCp was found in the angiosperms and originated in early chloroplast evolution through duplication of the cytosolic gapC gene [15].

In spite of the low gene expression level of GAPCps in contrast with cytosolic GAPDHs, GAPCp still participates in glycolytic energy production and metabolic regulation in non-green plastids [12,16,17]. GAPCp also is an important metabolic connector of carbon and nitrogen metabolism through the phosphorylated pathway of serine biosynthesis. Additionally, studies have shown that GAPCp1 and GAPCp2 are located in the chloroplast in Arabidopsis [6]. Mutations in the GAPCP gene cause metabolic abnormalities in the triose phosphate transporter (TPT) [18]. Transcriptome and metabolomic analysis have shown that the lack of GAPCp in plants can disrupt the synthesis of major metabolites such as carbon, nitrogen, glycine and glutamine [19]. In Arabidopsis, AtGAPCp1 and AtGAPCp2 may have links to ABA signal transduction and also have a central role in plant primary metabolism and pollen development [20]. Furthermore, the expression of AtGAPC 1 gene in shoots was induced to varying degrees by cold, osmotic, salinity and drought stresses at early stages [21]. Despite several previous studies, the precise role of GAPC $p$ in wheat resistance against abiotic stresses remains unclear. Therefore, it is important to understand the regulatory mechanism of how TaGAPCPs work in conferring wheat resistance to abiotic stress.

To investigate the relationship between transcriptional levels of TaGAPCP genes and abiotic stress tolerance, TaGAPC 1 gene was cloned and analyzed. Its expression under abiotic stresses was measured by qRT-PCR. In addition, the prey protein Cyt b6f interacting with the TaGAPCp1 protein was screened by $\mathrm{Y} 2 \mathrm{H}$, and was further verified by yeast co-transformation and BiFC analysis. Further experiments demonstrated that the expression of $\mathrm{Cyt}$ b6f was significantly elevated under $\mathrm{H}_{2} \mathrm{O}_{2}$ stress. Surprisingly, we found that Cyt b6f has peroxidase activity due to its carotenoids. In conclusion, the results of this study revealed that TaGAPCp1 was indeed involved in the drought stress response of wheat and the stress resistance process of TaGAPCp1 might be accomplished by $\mathrm{H}_{2} \mathrm{O}_{2}$-mediated ABA signaling pathway.

\section{Results}

\subsection{Identification and Sequence Analysis of TaGAPCp1 Gene in Wheat}

TaGAPC 1 gene is located on the 6AS chromosome of wheat. The length of TaGAPCp1 cDNA was $1526 \mathrm{bp}$, and a complete open reading frame (ORF) of $894 \mathrm{bp}$ encoding a deduced protein of 297 amino acids was obtained. Gene Structure Display Server showed that TaGAPCp1 contains 9 exons and 8 introns (Figure 1b). The enzyme with a predicted relative molecular mass of $31.54 \mathrm{kDa}$ and an isoelectric point of 6.08 exists as a tetramer of identical subunits (Figure S1b), each of which contains two conserved functional domains; an NAD-binding domain (InterPro: IPR0208), and a highly conserved catalytic domain (InterPro: IPR0208) as revealed by the Conserved Domain Database. Figure S1b shows that the tertiary structure of TaGAPCp1 is symmetrically distributed, with Alpha helix accounting for $25 \%$ and $\beta$ strand accounting for $30 \%$. Alignment of the amino acid sequence of GAPCps were given in Figure 1a. The results revealed that the amino acid sequence of TaGAPCp1 is shorter than other GAPCps, but the similarity with AtGAPCps was about $80 \%$.

Analyzing the evolutionary relationship of this gene subfamily from different species revealed the evolution of their function and disclosed the potential feature. To further characterize the GAPCp1 protein, the deduced protein and other GAPDHs from Arabidopsis thaliana were aligned by Clustalx and MEGA6.0 software via the neighbor-joining algorithm (Figure S1a). The alignment results revealed that TaGAPCp1 was very similar to AtGAPCps proteins and belonged to a clade of plant GAPCps based on the previously genome-wide identification and characterization of glyceraldehyde-3-phosphate dehydrogenase genes family in wheat [14]. 
(a) AtGAPCp1.seq AtGAPCp2 .seq TaGAPCp1.seq

AtGAPCp1.seq AtGAPCp2 . seq TaGAPCp1.seq

AtGAPCp1.seq AtGAPCp2 . seq TaGAPCp1.seq

AtGAPCp1.seq AtGAPCp2 . seq TaGAPCp1.seq

AtGAPCp1.seq AtGAPCp2 . seq TaGAPCp1.seq

AtGAPCp1.seq AtGAPCp2 . seq TaGAPCp1.seq

MAFSSILRSAASYTVAAPRPDFFSSPASDHSKVISSIGFSRNIKPSRESSGISSSIQNGNARSVQPIKATA MALSSILRSAAT . SAAA PRVELYPSSSYNHSCVTSSIGFSHSITSSRFS. GAAVSTGKYNAKRVCXPIKATA

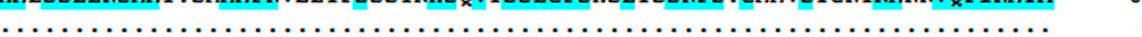

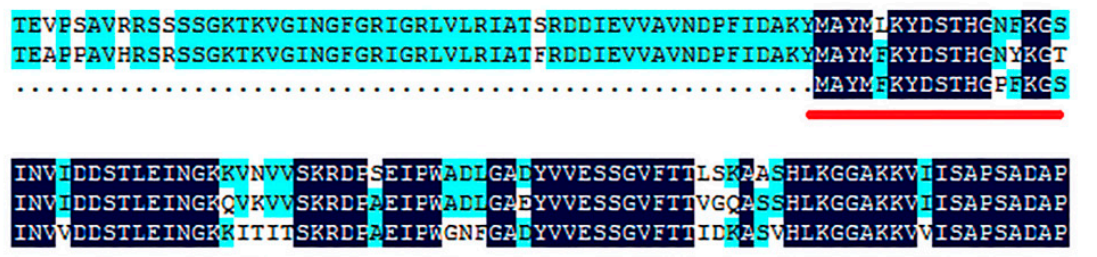

142
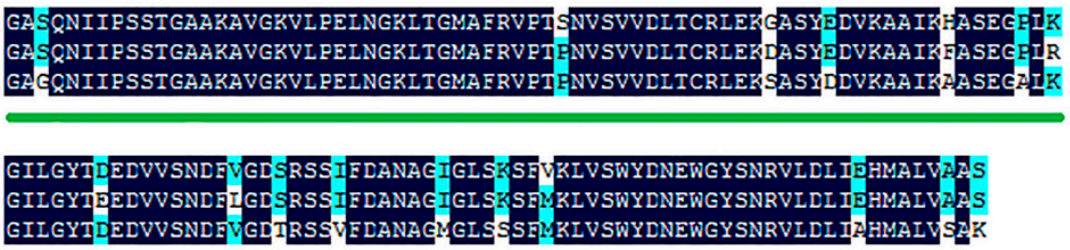

(b)

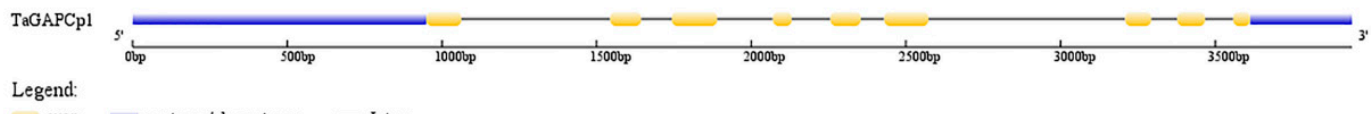

Legend:

exon $=$ upstream/ downstream - Intron

Figure 1. Sequence analysis. (a) Alignment of the Amino acid sequence of TaGAPCps. The identical and $75 \%$ amino acid sequence similarity are separately indicated by mazarine and green color. Red underlined, Glyceraldehyde 3-phosphate dehydrogenase, NAD(P) binding domain (IPR0208); green underlined, Glyceraldehyde 3-phosphate dehydrogenase, catalytic domain (IPR0208). (b) Schematic diagram for exons/introns and upstream/downstream structures of TaGAPCp1. Exons, introns, upstream/downstream are indicated by yellow boxes, black horizontal lines, and blue boxes, respectively.

\subsection{TaGAPCp1 Responds to Abiotic Stresses}

To reveal the inducible expression patterns of TaGAPC 1 in response to abiotic stresses, qRT-PCR was performed in a Bio-Rad CFX96 system (Bio-Rad Laboratories, Hercules, CA, USA) using the SYBR Green method. According to the qRT-PCR analysis, the expression of TaGAPCp1 gene in wheat seedling leaf was induced to varying degrees by different chemicals (polyethylene glycol (PEG), $\mathrm{NaCl}, \mathrm{ABA}, 4{ }^{\circ} \mathrm{C}$ and $\mathrm{H}_{2} \mathrm{O}_{2}$ ) at early stages. Exposed to drought stress (PEG), the expression of wheat $T a G A P C p 1$ was significantly up-regulated, peaking at $6 \mathrm{~h}$. The ABA hormone treatment directly up-regulated expression of TaGAPCp1, especially at $6 \mathrm{~h}$. During low temperature and salt treatment, TaGAPC 1 initially showed slight up-regulated expression and was down-regulated later. However, $\mathrm{H}_{2} \mathrm{O}_{2}$ treatment resulted in up-regulation of TaGAPCp1 obviously, peaking at $6 \mathrm{~h}$ (Figure 2a-e). The expression of TaGAPC $p 1$ gene in wheat seedling root was basically consistent with leaf and it was generally increased first and then decreased (Figure $2 \mathrm{f}-\mathrm{j}$ ). These results indicate that the expression of TaGAPC 1 in both leaves and roots was increased under these abiotic stresses relative to the control. However, the up-regulation response of TaGAPCp1 under the stress of PEG, ABA, and $\mathrm{H}_{2} \mathrm{O}_{2}$ was significant, and the up-regulation response was unapparent under low temperature and salt stress. 
(a)

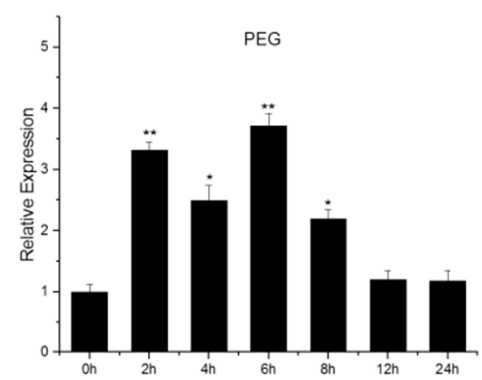

(d)
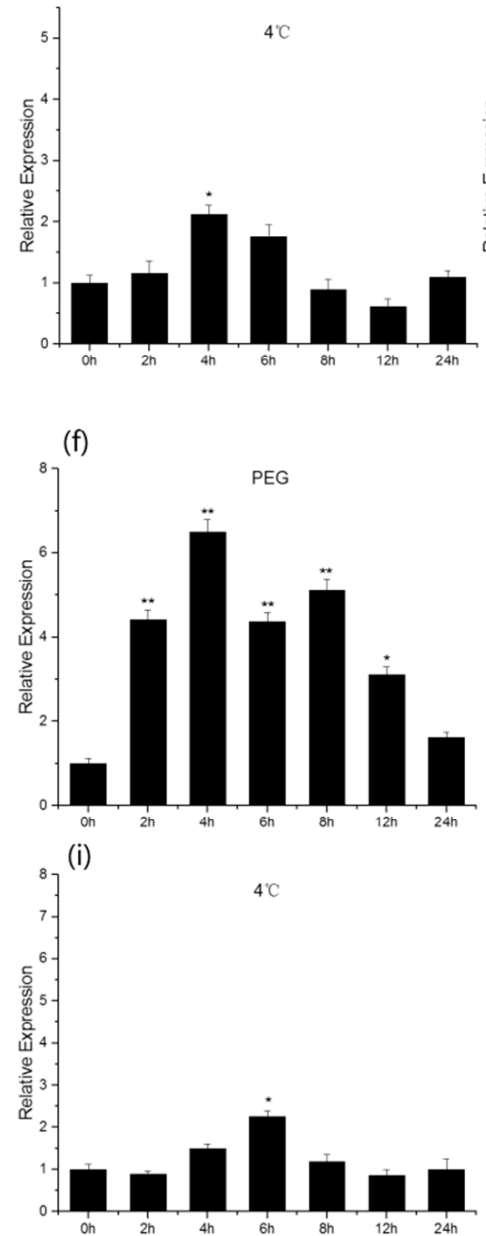

(b)

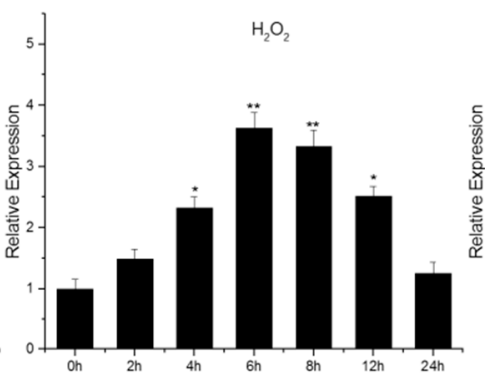

(c)

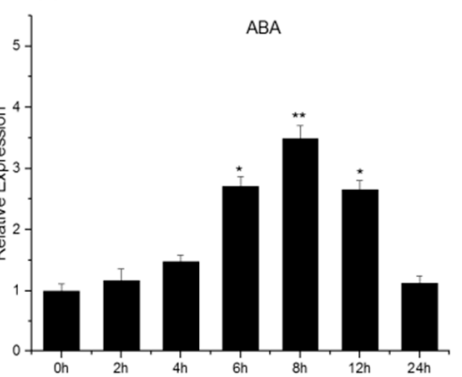

(e)

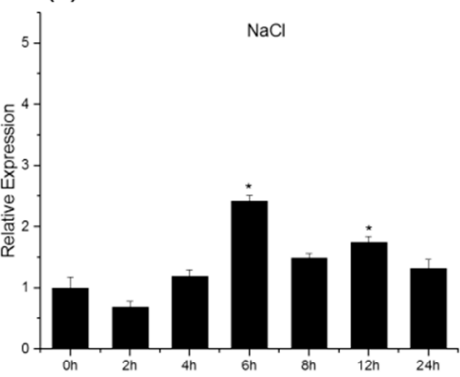

(g)
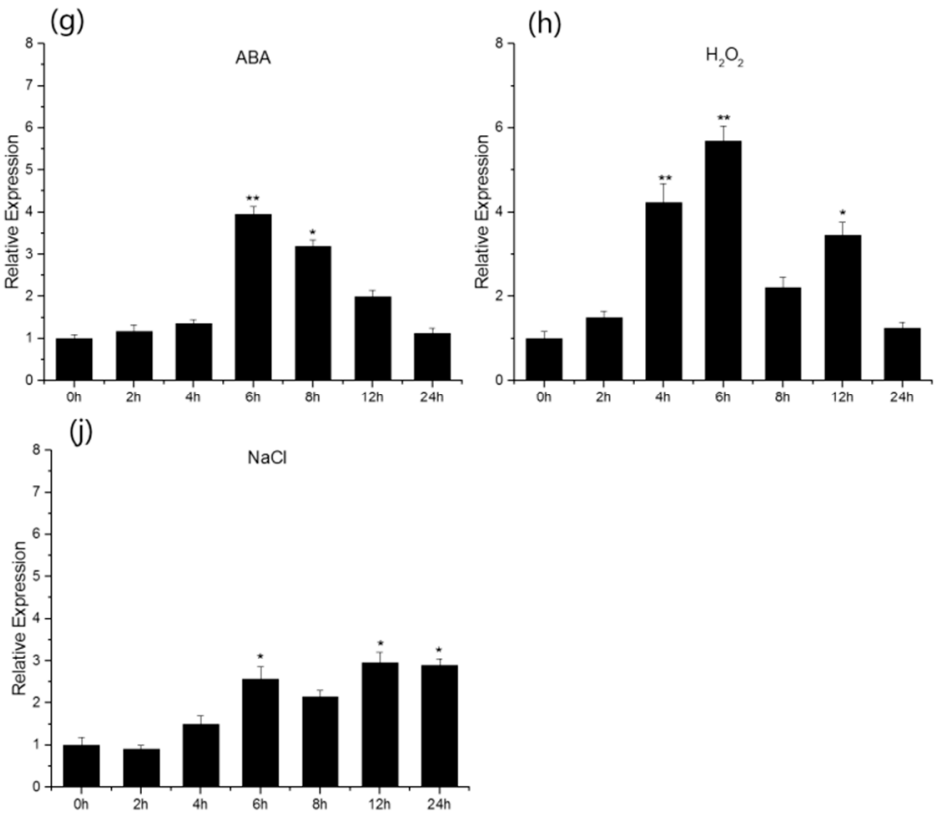

Figure 2. Expression profiles of TaGAPCp1 in wheat. (a-e) expression patterns of TaGAPCp1 in wheat leaves in response to various abiotic stresses: PEG, ABA (abscisic acid), $\mathrm{H}_{2} \mathrm{O}_{2}, 4{ }^{\circ} \mathrm{C}, \mathrm{NaCl}$. $(\mathbf{f}-\mathbf{j})$ Expression patterns of TaGAPCp1 in wheat roots in response to various abiotic stresses: PEG, ABA (abscisic acid), $\mathrm{H}_{2} \mathrm{O}_{2}, 4{ }^{\circ} \mathrm{C}, \mathrm{NaCl}$. Significant differences were detected by SPSS analysis. ${ }^{*} p<0.05$, ** $p \leq 0.01$.

To further investigate how intracellular TaGAPC 1 was maintained in response to drought stress, relative expression of TaGAPCp 1 was determined in stress-treated seedlings. As shown in Figure $3 \mathrm{~b}$, the expression of TaGAPCP1 gene was up-regulated after PEG and ABA treatment alone, but its expression decreased significantly after pretreatment with sodium tungstate solution (Tungstate). However, there was no significant difference between the expression level of TaGAPCP1 after PEG stress alone and the amount of expression after treatment with dimethylthiourea (DMTU) (Figure 3a). 
Therefore, it is speculated that ABA may be involved in the regulation of TaGAPCp1 gene expression under PEG stress.

After treating of OE-TaGAPCp1 and wild-type (WT) leaves by ABA, it was observed that the stomatal size of both became smaller with the increase of ABA concentration, but it was clear that the OE-TaGAPCp1 leaf stomata was smaller than WT (Figure 3c). This result demonstrated that TaGAPCp1 plays an important role in ABA-mediated stomata closure. Similarly, we found that the leaf stomata of both of OE-TaGAPCp1 and WT became smaller as the concentration of $\mathrm{H}_{2} \mathrm{O}_{2}$ increased (Figure 3d). However, the leaf pores of OE-TaGAPC 1 were smaller relative to WT under the same concentration of $\mathrm{H}_{2} \mathrm{O}_{2}$ treatment. These results revealed that $\mathrm{H}_{2} \mathrm{O}_{2}$ might act as a signal substance in ABA-mediated stomatal closure.

(a)

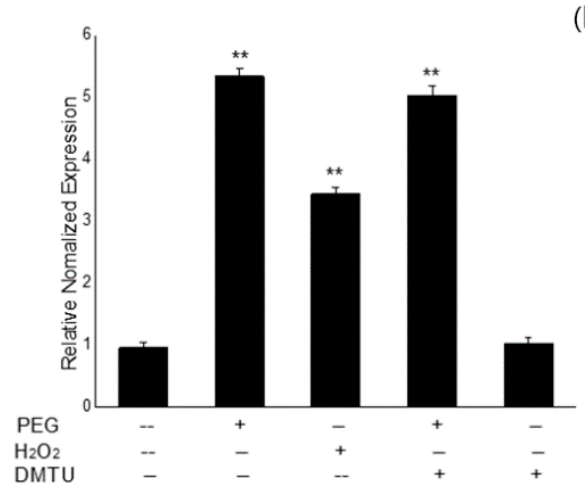

(c)

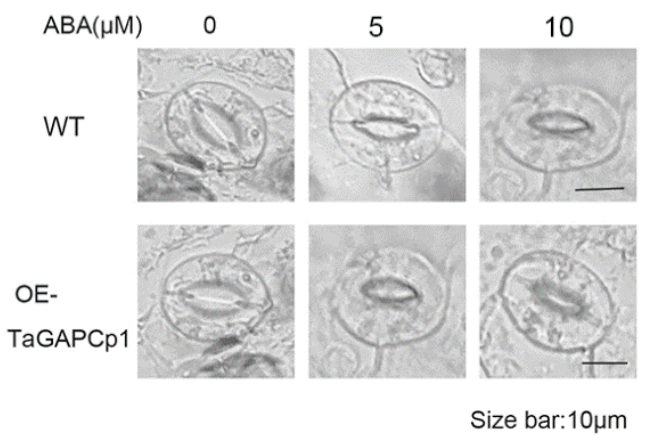

(b)

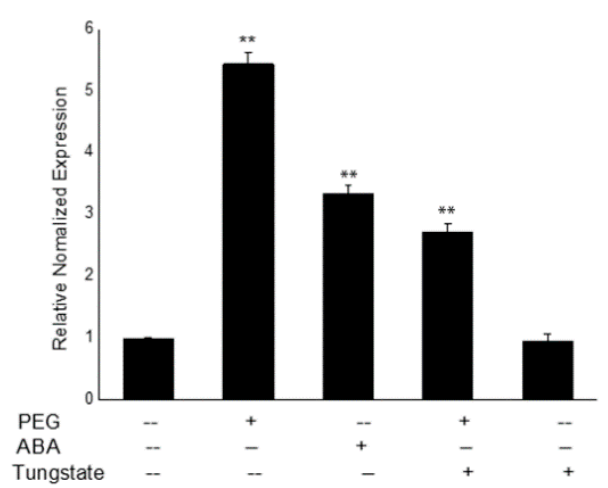

(d)

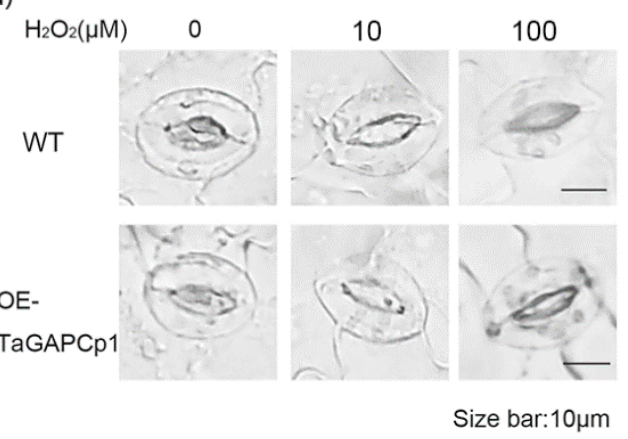

Figure 3. Effects of ABA and $\mathrm{H}_{2} \mathrm{O}_{2}$ inhibitors on the expression of TaGAPCp1 in wheat and the effects of $\mathrm{ABA}$ and $\mathrm{H}_{2} \mathrm{O}_{2}$ on the stomatal of transgenic arabidopsis leaves. (a) expression of aGAPCp1 gene in wheat seedling leaves under PEG stress after pretreatment with $\mathrm{H}_{2} \mathrm{O}_{2}$ inhibitor (dimethylthiourea (DMTU)). (b) expression of TaGAPCp1 gene in wheat seedling leaves under PEG stress after ABA inhibitor (tungstate) pretreatment. Bars are shown as the mean \pm Standard Deviation (SD). Significant differences were detected by SPSS analysis. ${ }^{*} p<0.05,{ }^{* *} p \leq 0.01$. (c,d) Stomatal size of WT and OE-TaGAPCp1 plants. Stomatal closure was observed after incubation of mature leaves in ABA $(0,5$ and $10 \mu \mathrm{M})$ and $\mathrm{H}_{2} \mathrm{O}_{2}(0,10$, and $100 \mu \mathrm{M})$ buffers for $2 \mathrm{~h}$, respectively. Each experiment was performed in triplicate. $\mathrm{Bar}=10 \mu \mathrm{m}$.

\subsection{TaGAPCp1 Is Localized to the Plastid}

The putative localization of TaGAPCp1 protein was identified by ChloroP prediction server, revealing that it is localized to the plastid. The CDS of TaGAPCp1 was fused with that of GFP under the control of the Cauliflower mosaic virus (35S) promoter to generate a construct expressing a TaGAPCp1-GFP fusion protein (Figure 4a). This fusion vector was used for a more particular knowledge of the subcellular localization of TaGAPCp1. Confocal microscopic examination demonstrated that the TaGAPCp1-GFP fusion vectors were expressed slightly in the plastid of the 
transformed protoplasts, whereas the pCaMV35S: GFP protein was present throughout the whole cells. These results demonstrated that TaGAPCp1 is probably a plastid protein (Figure $4 \mathrm{~b}$ ).

(a)

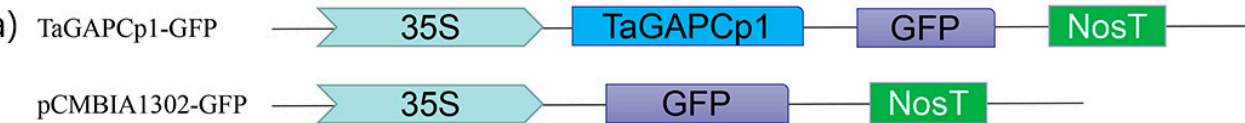

(b)
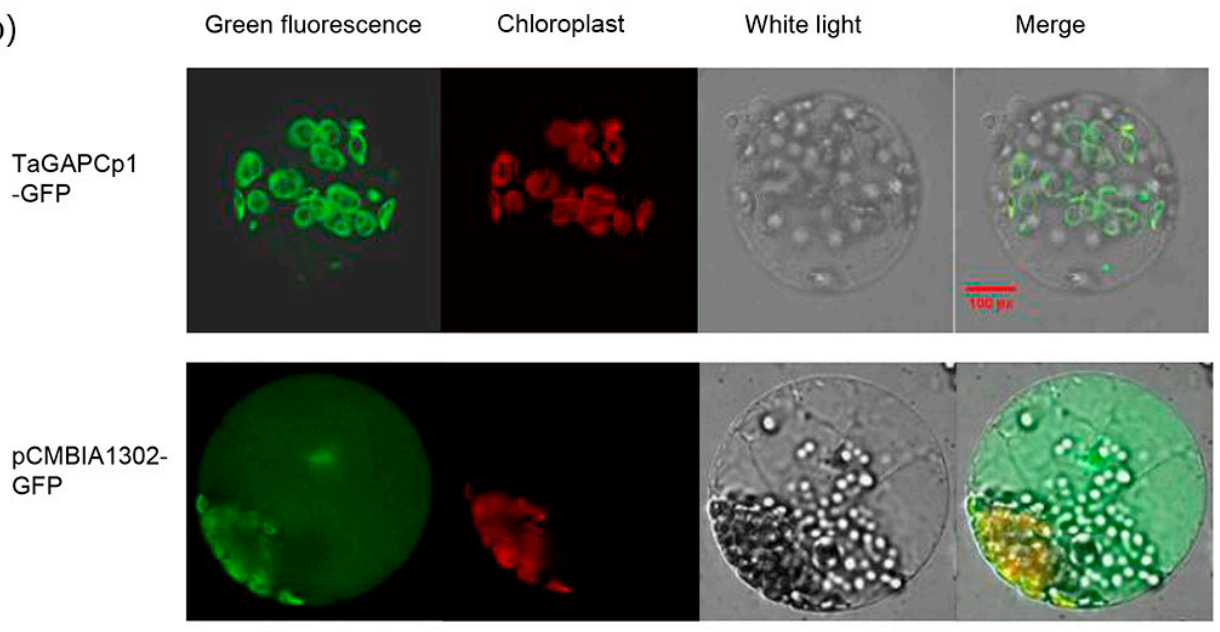

Figure 4. Subcellular localization of TaGAPCp1 in tobacco cells. (a) Structure of TaGAPCp1-GFP fusion expression vector. (b) The images showed the expression of the pCaMV35s: TaGAPCp1-GFP fusion protein in tobacco cells. All of the images were obtained using a confocal microscope. Bar $=20 \mu \mathrm{m}$.

\subsection{Screening for the Interacting Proteins of TaGAPCp1}

Yeast two-hybrid $(\mathrm{Y} 2 \mathrm{H})$ is a method for identifying interactions between proteins in yeast cells based on transcription factors in the transcriptional regulation of eukaryotic genes [22]. In this study, the wheat cDNA library (prey vector) and bait protein expression plasmid pGBKT7-TaGAPCp1 were constructed, and the full-length of TaGAPCp1 CDS was fused to GAL4 DNA-binding domain. The expression of the bait vector pGBKT7-TaGAPCp1 in Y2HGold Yeast Strain was verified by colony PCR and agarose gel electrophoresis. Colony PCR of the Y2HGold Yeast Strain transformed with the pGBKT7-TaGAPCp1 plasmid showed bands by gel electrophoresis, whereas the colony PCR of the Y2HGold Yeast Strain transformed with the pGBKT7 plasmid had no band (Figure 5a). It indicated that the pGBKT7-TaGAPCp1 plasmid and the pGBKT7 plasmid were both successfully transformed into Y2HGold Yeast Strain.

When introduced into yeast $Y 2 \mathrm{HGold}$ Yeast Strain, the absence of blue colonies on the SDO/X plates and no colony growth on the SDO/X/A plates indicated that pGBKT7 and pGBKT7-TaGAPCp1 did not autonomously activate the reporter gene. This indicates that pGBKT7-TaGAPCp1 does not activate MEL1 and AUR1-C reporter gene expression, i.e., glyceraldehyde triphosphate dehydrogenase does not have self-activation. In addition, toxicity tests indicated that the TaGAPCp1 was not toxic to yeast. First, because the size and growth conditions of the colonies were comparable to Y2HGold Yeast Strain transformed with the pGBKT7 empty vector (Figure 5b). Secondly, the concentration of the bacterial liquid containing pGBKT7-TaGAPCp1 was substantially equal to the concentration of the bacterial liquid containing pGBKT7 empty vector (Figure S2). The autoactivation and toxicity test indicated that the constructs were suitable for use in $\mathrm{Y} 2 \mathrm{H}$ screening.

The bait strains and wheat cDNA libraries were used for hybrid screenings. After hybridization, the total culture was spotted onto DDO/X/A plates after $4 \mathrm{~h}$ incubation. This high stringency screening was repeated at least 2-3 times. There were 186 positive clones identified through screening on double dropout medium DDO/X/A and total of 64 colonies were grown at QDO/X/A solid medium. After two re-identifications on $\mathrm{QDO} / \mathrm{X} / \mathrm{A}$ solid medium, 11 colonies were screened on the 
defective medium, and all of these colonies grew well and turned blue (Figure $5 \mathrm{c}$ ). The yeast plasmid PCR results showed that all of the nine selected clones had bands, and the sequences were of different lengths and distributed in the range of 1000-2000 bp (Figure 5d). Sequence (Table S2) analysis of the plasmids indicated that these 11 plasmids, represent 7 homologous cDNA (Table 1).

Table 1. Basic Local Alignment Search Tool (BLAST) result for interacting proteins between TaGAPCp1 and cDNA wheat library.

\begin{tabular}{cccc}
\hline Clone & Name & Functions & GenBank \\
\hline 1,5 & $\begin{array}{c}\text { Tauschii dormancy-associated protein } \\
\text { homolog, mRNA }\end{array}$ & Involved in plant stress resistance & XM_020318726.1 \\
\hline 2 & $\begin{array}{c}\text { Tauschii cytochrome b6-f complex } \\
\text { iron-sulfur subunit, mRNA (Cyt b6f) }\end{array}$ & $\begin{array}{c}\text { Involved in photoreactive electron } \\
\text { transport }\end{array}$ & XM_020345741.1 \\
\hline 3,11 & $\begin{array}{c}\text { Tauschii ATP-dependent Clp protease } \\
\text { proteolytic subunit 6, mRNA }\end{array}$ & Involved in Stress response & XM_020331538.1 \\
\hline $4,8,10$ & $\begin{array}{c}\text { Tauschii ribulose-1,5-bisphosphate } \\
\text { carboxylase, complete cds }\end{array}$ & Involved in Calvin cycle & KT288199.1 \\
\hline 6 & Tauschii GATA transcription factor, mRNA & $\begin{array}{c}\text { Transcription factor with a special zinc } \\
\text { finger structure }\end{array}$ & XM_020324318.1 \\
\hline 7 & Tauschii probable E3 ubiquitin-protein \\
ligase, mRNA & $\begin{array}{c}\text { One of the key enzymes in the } \\
\text { ubiquitination process }\end{array}$ & XM_020328679.1 \\
\hline 9 & Tauschii protein SGT1, mRNA & $\begin{array}{c}\text { Participate in the regulation of plant } \\
\text { disease resistance }\end{array}$ & KJ907387.1 \\
\hline
\end{tabular}

(a)

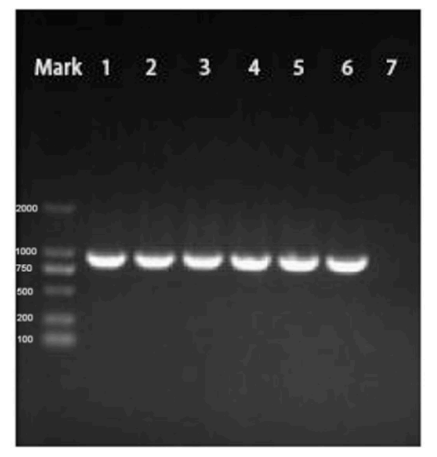

(c)

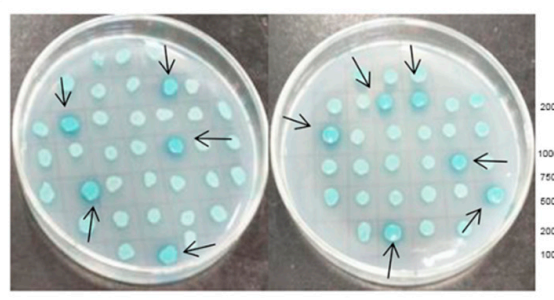

(b)

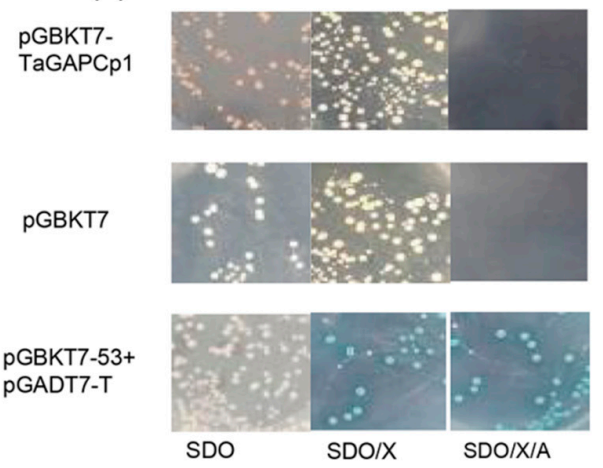

(d)

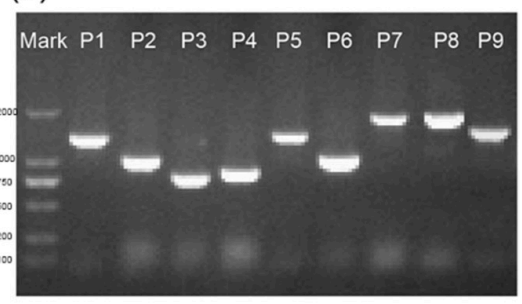

Figure 5. Screening of yeast two-hybrid. (a) Gel electrophoresis analysis of colony PCR about the Y2HGold Yeast Strain transformed with pGBKT7-TaGAPCp1 plasmids (number 1-6) and pGBKT7 plasmids (number 7). Mark is DL 2000 molecular marker and from top to bottom are 2000, 1000, 750, 500, 200 and 100. (b) Determination of autoactivation and toxicity of the bait vector in Y2HGold Yeast Strain on different selection mediums. The first line was the result of transforming pGBKT7-TaGAPCp1 into Y2HGold Yeast Strain alone; the second line (converting pGBKT7 to Y2HGold Yeast Strain) was used as a negative control; the third line was to convert pGBKT7-53 and pGADT7-T into Y2HGold Yeast Strain as positive control. (c) Screening diagram of TaGAPCp1. Blue clones indicated positive results, whereas white or absent clones were negative; (d) PCR amplification of positive prey plasmids by T7 primers. Lane P1-P9: PCR products amplified from the positives P1-P9 (responding to prey vectors P1-P9); Lane Mark: DL 2000 marker. 


\subsection{Verify the Interaction between TaGAPCp1 and the Interacting Proteins}

Each potential positive prey plasmid (pGADT7-X vector) and pGBKT7-TaGAPCp1 was co-transformed into Y2HGold Yeast Strain, respectively. Figure 6a shows that colonies were observed on $\mathrm{QDO} / \mathrm{X} / \mathrm{A}$ plates of P2, P3, P4, and PC, and no colonies were observed on the other plates. To eliminate the false positive result, controls were employed in this experiment. Negative controls for P3 and P4 (Y2HGold Yeast Strain transformed with pGBKT7 empty bait plasmid and pGADT7-X vector) showed colonies on $\mathrm{QDO} / \mathrm{X} / \mathrm{A}$ plates, while no colonies were observed on $\mathrm{QDO} / \mathrm{X} / \mathrm{A}$ plate for P2 negative control. On the other hand, blue colonies of the positive control (Y2HGold Yeast Strain containing pGADT7-T and pGBKT7-53) were observed on the QDO/X/A plate. Therefore, there is an interaction relationship between P2 and TaGAPCp1. P2 was identified as Cytochrome b6-f Complex Iron-sulfur Subunit (Cyt b6f) protein (GenBank: XM_020345741.1) by DNA sequencing. Further confirming the interaction between Cyt b6f and TaGAPCp1 in wheat cells, pSPYNE-TaGAPCp1 (yellow fluorescent N-terminal fragment protein) and pSPYCE-Cyt b6f (C-terminal fragment of a yellow fluorescent protein) recombinant vector were transformed to tobacco and prepared protoplasts; the fluorescence signal was mainly observed in the cytoplasm. In contrast, no positive signals were observed when pSPYNE-TaGAPCp1 and pSPYCE as well as pSPYNE and pSPYCE-Cyt b6f constructs were co-transformed into tobacco protoplasts (Figure 6b).

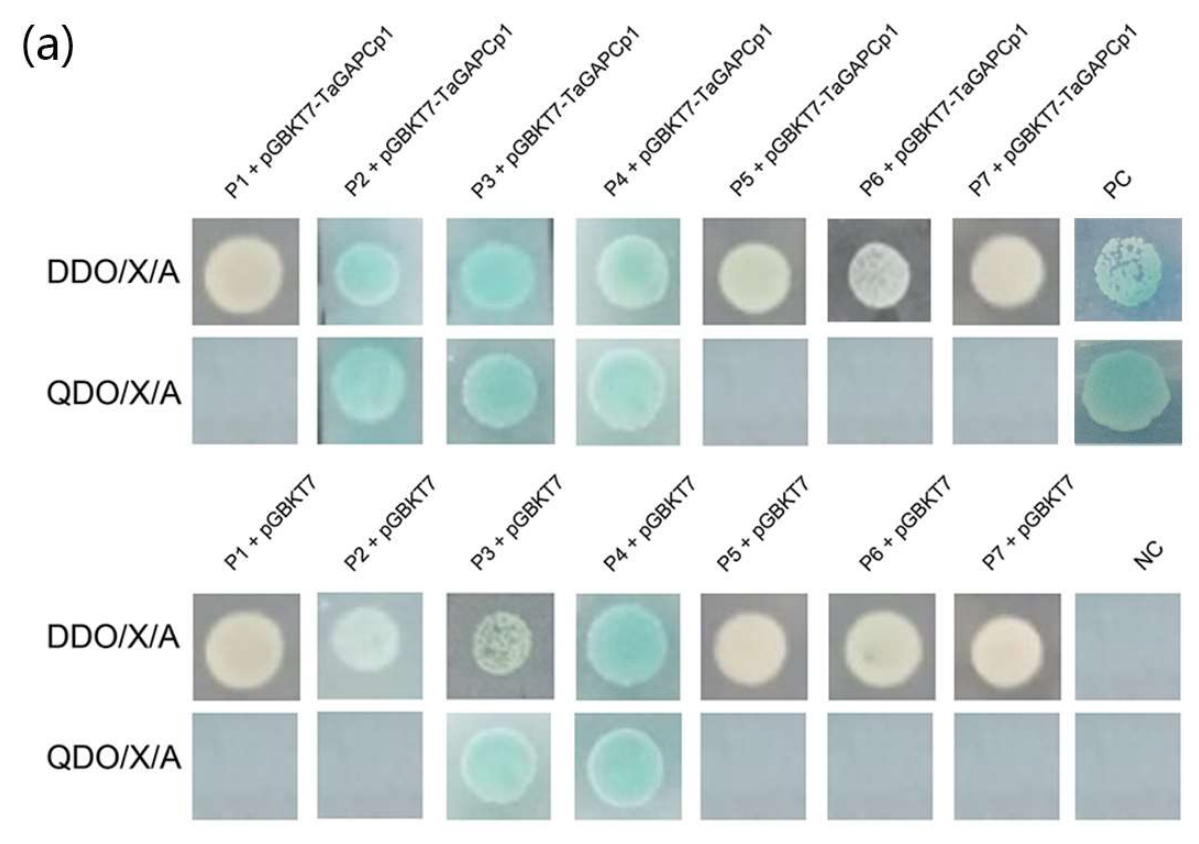

Figure 6. Cont. 


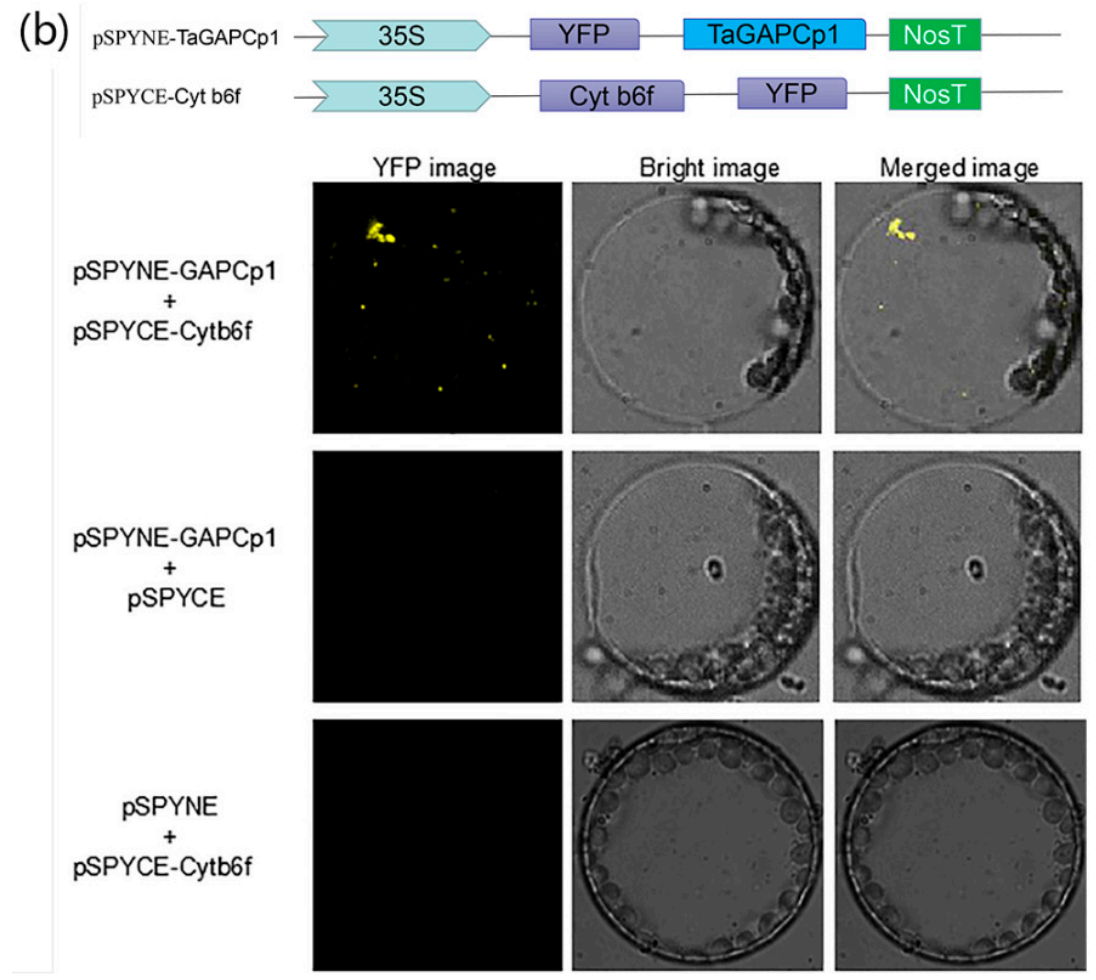

Figure 6. Identification of prey proteins interacting with TaGAPCp1. (a) Confirmation of true positive clones by small-scale Y2H assay. First row and second row: pGBKT7-TaGAPCp1 plasmid and the respective prey 1 to prey 7 plasmids (P1-P7) was co-transformed into Y2HGold Yeast Strain then staked on QDO/X/A plates and DDO/X/A plates, respectively. Third row and fourth row: pGBKT7-TaGAPCp1 plasmid and pGBKT7 empty bait was co-transformed into Y2HGold Yeast Strain then staked on QDO/X/A plates and DDO/X/A plates, respectively. PC indicates a positive control, NC indicates a negative control. (b) BiFC assay of the interaction between TaGAPCp1 and Cyt b6f proteins in tobacco leaf protoplasts. The pSPYNE-TaGAPCp1 and pSPYCE-Cyt b6f constructs were co-infiltrated in tobacco by Agrobacterium. The YFP fluorescence was detected by confocal laser scanning microscopy. Co-transformants of pSPYNE-TaGAPCp1 and pSPYCE as well as pSPYNE and pSPYCE-Cyt b6f were used as negative controls. Bar $=20 \mu \mathrm{m}$.

\subsection{Analysis of the Interacting Protein Cytb6f}

The Cytb6f gene ORF sequence is $669 \mathrm{bp}$ and encodes 222 amino acids. In addition, the analysis results of ProtParam software showed that the Molecular weight of the protein was $23.7 \mathrm{kD}$, the Theoretical pI was 8.47 and the instability index (II) was computed to be 25.34, classifying the protein as stable. Moreover, the average hydrophilicity index Grand average of hydropathicity (GRAVY) was -0.071 and this identified the protein as hydrophilic. There is considerable evidence to suggest that Cytb6f may exist as a dimer, with each monomer composed of eight subunits distributed on the thylakoid membrane [23]. In plants, these thylakoid membrane protein complex subunits are encoded by chloroplasts and nucleus. To investigate the activity of Cyt b6f under abiotic stress, the effects of PEG, ABA, and $\mathrm{H}_{2} \mathrm{O}_{2}$ on wheat leaves were examined. As shown in Figure $7 \mathrm{~b}$, the expression level of Cyt b6f showed a significant increase under $\mathrm{H}_{2} \mathrm{O}_{2}$ stress and reached a peak at $2 \mathrm{~h}$. The results indicate that $\mathrm{H}_{2} \mathrm{O}_{2}$ was first proposed as a signaling molecule involved in the process of Cyt b6f response to abiotic stress. Studies also have reported that Cyt b6f monomer molecules contain one molecule of natural component chlorophyll a (Chl a) and one molecule carotenoid [24,25]. Additionally, the chlorophyll content in OE-TaGAPCp1 plants was significantly higher than that in WT (Figure 7a). 
(a)

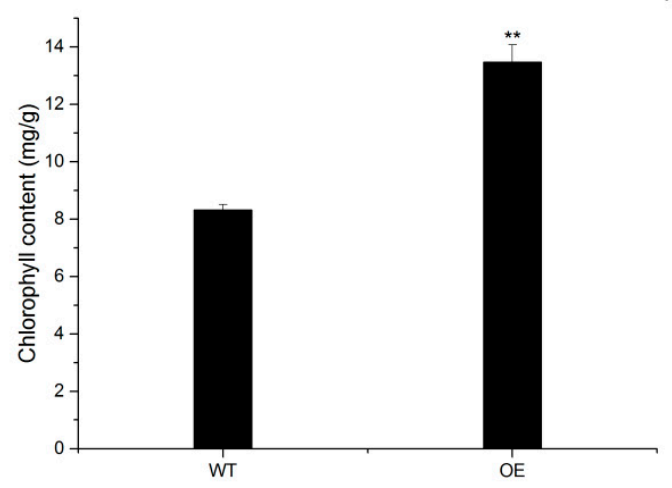

(b)

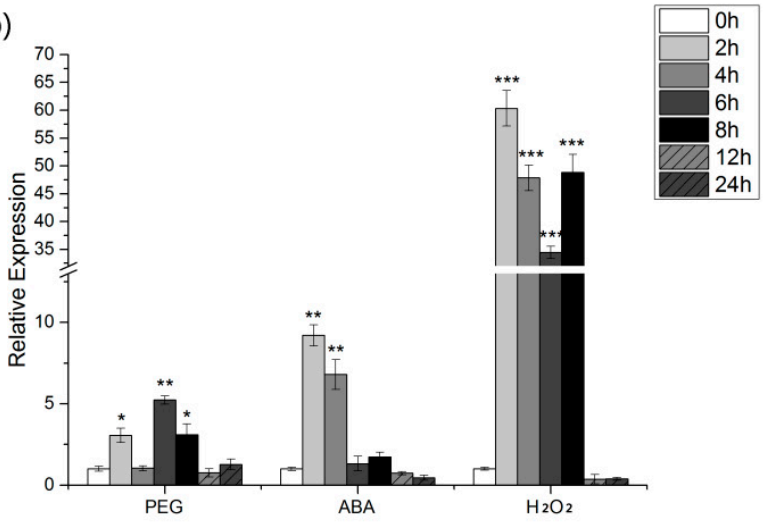

Figure 7. Chlorophyll content in Arabidopsis plants and Expression patterns of Cyt b6f in wheat leave. (a) Chlorophyll content in OE-TaGAPCp1 plants and wild-type plants. OE represents OE-TaGAPCp1 plants; WT represents wild-type plants. (b) Expression patterns of Cyt b6f in wheat leaves in response to various abiotic stresses: $\mathrm{PEG}, \mathrm{ABA}$ and $\mathrm{H}_{2} \mathrm{O}_{2}$. Bars are shown as the mean $\pm \mathrm{SD}$. Significant differences were detected by SPSS analysis. ${ }^{*} p<0.05 ;{ }^{* *} p \leq 0.01 ;{ }^{* * *} p \leq 0.001$.

\section{Discussion}

\subsection{TaGAPCp1 Plays a Key Role in Abiotic Stresses}

Plastidial GAPCps play an important physiological role in plant function [26]. It has been reported that TaGAPCp1 is involved in plastidial glycolytic pathway and plays a specific role in glycolytic energy production in non-green plastids and chloroplasts [6]. In this study, the TaGAPCp1 was identified and analyzed from Chinese Spring wheat (Figure 1). The gene shares high similarity with GAPCps members of other species, which further illustrate that the GAPDH coding region is highly conserved [27].

The substrate of GAPCp, glyceraldehyde-3-phosphate, is the first precursor of the methyl-erythritol phosphate pathway responsible for ABA biosynthesis in the plastids $[5,6]$. In the present study, evidence showed that TaGAPCp1 is a positive regulator of wheat tolerance to drought, $\mathrm{ABA}$ and $\mathrm{H}_{2} \mathrm{O}_{2}$ stress. The relative expression levels of TaGAPC 1 in plants under drought, ABA and $\mathrm{H}_{2} \mathrm{O}_{2}$ stress were significantly higher than those in non-stressed plants (Figure 2). The same results indicated that the enzyme activity of GAPDH in Craterostigma plantagineum substantially increased under ABA treatment [28]. These protective responses of plants might be primarily regulated by synergistic and antagonistic actions of signaling molecules. In any case, these results indicate that TaGAPCp1 is an important player in the response of wheat to drought, $\mathrm{ABA}$ and $\mathrm{H}_{2} \mathrm{O}_{2}$ stress.

In addition, plant ABA plays an important role in plant responses to abiotic stress [29]. Additionally, plants rapidly inhibit stomatal opening under the control of ABA signaling pathway, in order to preserve water [30]. ABA hormones were reported to have a close connection with the signaling networks and the regulation of developmental processes responding to variously environmental stresses. ABA plays an important role in plant responses to abiotic stress [29]. It has been shown that the expression level of TaGAPC 1 was relatively high under the stress of PEG, although the expression level was significantly decreased after pretreatment with ABA inhibitor (Figure 3b). Thus, it could be speculated that drought stress may cause changes in the osmotic pressure of plant cells and then pass signals through the "osmotic sensing device" to the cells. Whereafter, a series of enzymes in the cell regulate the expression of TaGAPC 1 gene under drought stress through the ABA signaling pathway. Additionally, plants rapidly inhibit stomatal opening under the control of ABA signaling pathway (Figure 3c), in order to preserve water [30]. However, the leaf stomata of both of OE-TaGAPCp1 and WT became smaller after $\mathrm{H}_{2} \mathrm{O}_{2}$ treatment (Figure 3d). Therefore, TaGAPCp1 plays an important role in responding to water-deficient abiotic stress and it is likely to be regulated by the $\mathrm{H}_{2} \mathrm{O}_{2}$-dependent ABA signaling pathway. 


\subsection{The Interaction Protein Cyt b6f of TaGAPCp1 Has Peroxidase Activity}

The interaction protein Cyt b6f of TaGAPCp1 was obtained by yeast two-hybrid system (Figure 5) and verified by BiFC method (Figure 6b). This further illustrated the strong interaction between Cyt b6f and TaGAPCp1. Cyt b6f occupies a central position in the photosynthetic electron transport chain, bridging the photosynthetic reaction centers of PS I and PS II [31]. It may exist as a dimer, with each monomer composed of eight subunits [23]. These subunits evenly distribute on the thylakoid membrane. In plants, these thylakoid membrane protein complex subunits are encoded by chloroplasts and nucleus [28]. In addition, two cofactors, $\mathrm{Chl}$ a and carotenoids, have been identified in a 1:1:1 ratio with the monomeric Cyt b6f. It is worth mentioning that $\mathrm{Cyt} b 6 \mathrm{f}$ is also a heme-containing protein complex with peroxidase activity $[24,25]$.

\subsection{The Role of TaGAPCp1 in Drought Resistance Is Largely Dependent on $\mathrm{H}_{2} \mathrm{O}_{2}$-Mediated ABA Signaling Pathway}

On a molecular level, reactive oxygen species (ROS) was a severe problem of abiotic stress in plants [32]. Excessive ROS production could cause oxidative damage to the photosynthetic apparatus, block electron transport and decrease photosynthetic capacity [33]. More previous studies indicate that ROS would accumulate in stressful environments, such as drought, salinity, ABA, and other conditions [34-36]. It has been reported that carotenoids are important powerful antioxidants [37]. Because of the powerful antioxidant activity, carotenoids maintain ROS homeostasis and stabilize cellular membranes, thus improving plant abiotic stress tolerance $[32,38,39]$. In this study, the relative expression of Cyt b6f in wheat leaves was significantly increased under $\mathrm{H}_{2} \mathrm{O}_{2}$ stress (Figure $7 \mathrm{~b}$ ). We also found that TaGAPCp1 promotes the synthesis of chlorophyll a and carotenoids, which are the main component of Cyt b6f (Figure 7a). Furthermore, antioxidant carotenoid, the important constituents of Cyt b6f, may reduce ROS accumulation by inhibiting $\mathrm{H}_{2} \mathrm{O}_{2}$ production [32]. Carotenoids are also important precursors of phytohormones, including ABA [40]. Moreover, ABA can induce up-regulation of antioxidants such as SOD, CAT and carotenoids, thereby increasing the ability of plants to scavenge ROS [41]. Thus, ROS may participate in ABA signal transduction [42-45]. $\mathrm{H}_{2} \mathrm{O}_{2}$ is the main form of reactive oxygen species (ROS), which acts as a crucial signaling molecule in the ABA response pathway in guard cells $[46,47]$. Additionally, Cyt b6f is a major component of cyclic electron transport chain around PS I which plays an important role in dissipating excessive excitation energy [33]. Carotenoids play essential roles in various light-harvesting processes in plants and help protect the photosynthetic machinery from photo-oxidative damage. There are reports that the orange gene of sweet potato helps maintain carotenoid homeostasis and directly stabilize PSII to improve plant tolerance to environmental stress [39]. Therefore, we could speculate that Cyt b6f might play an important role in TaGAPCp1 response to drought and other stress processes through ABA signaling pathway (Figure 8). However, the activity of TaGAPCp1 and the interaction protein Cyt b6f were significantly increased under the stress of drought and $\mathrm{H}_{2} \mathrm{O}_{2}$ stress, respectively (Figure 8). It is also fully demonstrated that the role of TaGAPCp1 in drought resistance is largely determined by $\mathrm{H}_{2} \mathrm{O}_{2}$-mediated ABA signaling pathway. 


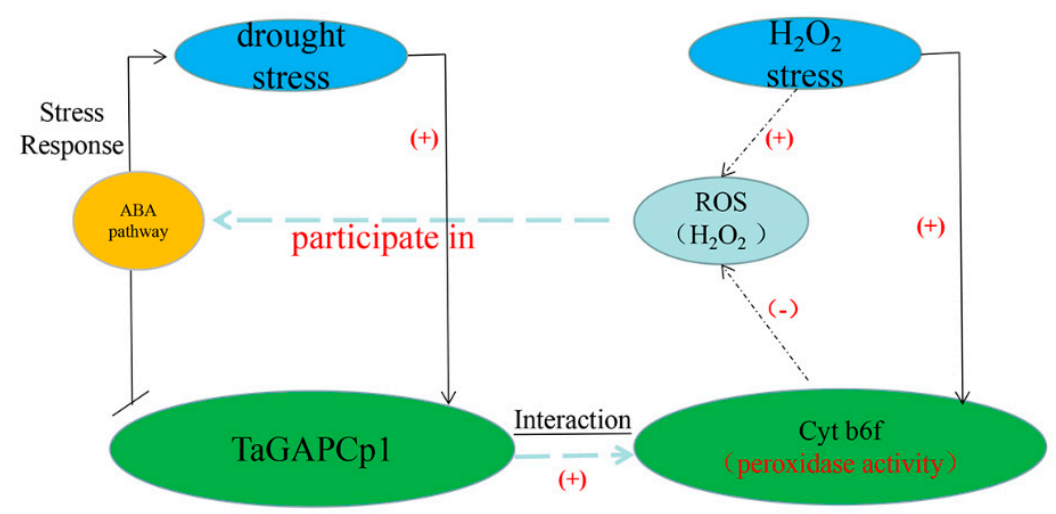

Figure 8. Model of how TaGAPCp1 responds to drought stress. Drought stress and $\mathrm{H}_{2} \mathrm{O}_{2}$ stress significantly increased the expression levels of TaGAPCp1 and Cyt b6f, respectively. TaGAPCp1 plays an active role in response to drought stress by $\mathrm{H}_{2} \mathrm{O}_{2}$-dependent $\mathrm{ABA}$ signaling pathway. The interaction between TaGAPCp1 and Cyt b6f has been confirmed. TaGAPCp1 also promotes the biosynthesis of chlorophyll, which is a natural component of Cyt b6f. Cyt b6f can reduce the accumulation of reactive oxygen species (ROS) and then respond to abiotic threats. Among them, (+) represents promotion and (-) represents inhibition. Straight lines represent direct effects and dashed lines represent indirect effects.

\section{Materials and Methods}

\subsection{Plant Materials and Abiotic Stresses}

Wheat seeds (Chinese Spring) were sterilized with $0.01 \% \mathrm{HgCl}_{2}$ and washed at least three times with distilled water. Sterilized seeds were grown hydroponically in glass dishes in full-strength Hoagland solution. Germinated seedlings were maintained under a relative humidity (RH) of $75 \%$ and 16/8 h (light/dark, $25 / 15^{\circ} \mathrm{C}$ ) photoperiod (light intensity of $250 \mu \mathrm{mol} \mathrm{m}{ }^{-2} \mathrm{~s}^{-1}$ ) for 14 days. The two-leaf-stage seedlings were immersed in $\mathrm{NaCl}(250 \mathrm{mM})$, water deficiency (20\% PEG 8000), $\mathrm{H}_{2} \mathrm{O}_{2}(10 \mathrm{mM})$, cold $\left(4^{\circ} \mathrm{C}\right)$ and $\mathrm{ABA}(100 \mu \mathrm{M}$ abscisic acid), respectively. All of the treatments and controls were sampled at $0,2,4,6,8,12$ and $24 \mathrm{~h}$ with three biological replicates, each of which composed of 6 wheat seedlings.

Furthermore, wheat seedlings were treated with $1 \mathrm{mM}$ sodium tungstate solution (Tungstate) for $6 \mathrm{~h}$ and prior to further treatment with PEG 8000 for more $6 \mathrm{~h}$. At the same time, seedlings treated with $20 \%$ PEG 8000, $100 \mu \mathrm{M}$ abscisic acid and $1 \mathrm{mM}$ sodium tungstate for $6 \mathrm{~h}$, respectively, were used as controls. The seedlings were also treated with $5 \mathrm{mM}$ DMTU for $6 \mathrm{~h}$, then treated with PEG 8000 for $6 \mathrm{~h}$; while those treated with $20 \%$ PEG8000, $10 \mathrm{mM} \mathrm{H}_{2} \mathrm{O}_{2}$ and $5 \mathrm{mM}$ DMTU for $6 \mathrm{~h}$, respectively, were used as a control. Tungstate was used as an ABA inhibitor and DMTU as an $\mathrm{H}_{2} \mathrm{O}_{2}$ inhibitor. The samples were immediately frozen in liquid nitrogen and stored at $-80^{\circ} \mathrm{C}$ for extraction of total RNA.

Arabidopsis seeds were germinated on 1/2 Murashige and Skoog (MS) medium containing 2\% sucrose and then transplanted into soil. The plants were grown at $16 / 8 \mathrm{~h}$ (light/dark, $25 / 15{ }^{\circ} \mathrm{C}$ ) photoperiod (light intensity of $250 \mu \mathrm{mol} \mathrm{m}{ }^{-2} \mathrm{~s}^{-1}$ ). To construct a TaGAPCp1 overexpressing plant (OE-TaGAPC $p 1$ plants), the coding region of TaGAPC 1 was introduced into the plant transformation vector pCAMBIA1302 under the control of the $35 \mathrm{~S}$ promoter. The construct was transformed into Agrobacterium and transformed into wild type Arabidopsis by invasive inflorescence.

\subsection{Identification and Sequence Analysis of TaGAPCp1}

The coding sequence of TaGAPCp1 (MF477938.1) was amplified from cDNA extracted from Chinese spring wheat leaves using primers TaGAPCp1-F and TaGAPCp1-R (Table S1) based on the nucleotide sequence of TaGAPCP1 and the amplified sequence was blasted against the Triticum aestivum databases (http://plants.ensembl.org/index.html). The exon-intron structures of gene were identified through the online Gene Structure Display Serve (http:/ /gsds.cbi.pku.edu.cn). To analyze 
the TaGAPCp1 protein well, the physical and chemical properties of the protein were determined on the ProtParam (https:/ / web.expasy.org/protparam/) and the sequence of amino acid was compared by DNAMAN6.0 (Lynnon Biosoft, San Ramon, CA, USA). In addition, the tertiary structure of TaGAPCp1 was predicted by SWISS-MODEL (http://swissmodel.expasy.org/). The sequence was determined using NCBI database (http:/ / www.ncbi.nlm.nih.gov/) and domains of the proteins were analyzed by the InterProScan (http://www.ebi.ac.uk/cgi-bin/iprscan/). Subsequently, a phylogenetic tree between species was constructed using the Neighbor-joining method in MEGA 6.0 software (Arizona State University, USA).

\subsection{Transcript Level of TaGAPCp1}

Total RNA was extracted from the wheat seedling by RNAios reagent kit (TaKaRa, Kusatsu, Japan) and the first strand of cDNA was synthesized using the PrimeScript ${ }^{\mathrm{TM}} \mathrm{RT}$ reagent kit (TaKaRa) according to the manufacturer's instructions. For the qRT-PCR analyses, the wheat $\beta$-actin was used as the internal reference. Quantitative real-time PCR was performed in a Bio-Rad CFX96 system (Bio-Rad Laboratories) using SYBR Premix Ex Taq (TaKaRa). The used primers are listed in Table S1. The volume of the PCR reaction was $20 \mu \mathrm{L}$ under the following conditions: $95^{\circ} \mathrm{C}$ for $30 \mathrm{~s}, 40$ cycles of $95^{\circ} \mathrm{C}$ for $5 \mathrm{~s}, 60^{\circ} \mathrm{C}$ for $30 \mathrm{~s}$, and melting curve analysis. The qRT-PCR analysis was accomplished with comparative $2^{-\Delta \Delta C t}$ method [48] by Bio Rad CFX Manager software and SPSS 20. Then the relative expression figure of TaGAPCp1 were showed via using Origin 8.0 (Microcal, CA, USA).

\subsection{Stomatal Aperture Measurement}

Mature leaves of 4-week-old Arabidopsis plants were immersed in stomatal opening solution $\left(30 \mathrm{mM} \mathrm{KCl}, 100 \mathrm{mM} \mathrm{CaCl}_{2}\right.$, and $10 \mathrm{mM} \mathrm{MES}, \mathrm{pH}$ 6.15) for $2 \mathrm{~h}$ at $22^{\circ} \mathrm{C}$ [49]. The treated leaves were transferred to treatment solutions containing different concentrations of $\mathrm{ABA}(0,10$, and $100 \mu \mathrm{M})$ and $\mathrm{H}_{2} \mathrm{O}_{2}(0,100$, and $200 \mu \mathrm{M})$. After incubating for $2 \mathrm{~h}$ under white light, the stomata of each exfoliated epidermis were observed [50].

\subsection{Subcellular Localization of TaGAPCp1}

To identify the subcellular localization of TaGAPCp1, the specific primers 1302F/R (Table S1) without the terminating codon were used to amplify the TaGAPCP1 coding sequence (CDS). PCR products were inserted into the corresponding sites of pCMBIA1302-GFP vector (digested with NcoI) with One Step Cloning Kit (Vazyme, Nanjing, China). The pCaMV35S:TaGAPCp1-GFP fusion vector was used for Agrobacterium-mediated transient transformation of 4-week tobacco epidermal cells and pCMBIA1302-GFP vector used as the control. Protoplasts isolated from tobacco epidermal cells maintain many of the same physiological responses and cellular activities as intact plants [51,52] GFP signals were photographed using an Andor Confocal Laser Scanning Microscopy (LSM710, Karl Zeiss, Jena, Germany).

\subsection{Screening of Proteins Interacting with TaGAPCp1 by Yeast Two-Hybrid Assay}

Yeast biology was directly used to construct a Mate \& Plate library via in vivo recombination between Chinese spring wheat cDNA and the Matchmaker prey vector pGADT7-Rec. The CDS of TaGAPC 1 was cloned into the pGBKT7 vector by primers TaGAPCp1-F/R (Table S1) and transformed into the yeast strain $\mathrm{Y} 2 \mathrm{H}$ Gold according to the manufacturer's instructions (Clontech, Mountain View, CA, USA). It was important to test the bait protein for auto-activation and toxicity prior to $\mathrm{Y} 2 \mathrm{H}$ screening. Thus, the pGBKT7-TaGAPCp1 and pGBKT7 empty vector were transformed into Y2HGold Yeast Strain, respectively. Subsequently, the cultures were separately plated on SD/-Trp (SDO), $\mathrm{SD} /-\operatorname{Trp} / \mathrm{X}-\alpha-\mathrm{Gal}(\mathrm{SDO} / \mathrm{X})$ and SD/-Trp/X- $\alpha-\mathrm{Gal} / \mathrm{AbA}(\mathrm{SDO} / \mathrm{X} / \mathrm{A})$ agar plates and incubated at $30{ }^{\circ} \mathrm{C}$ for 5 days. Among them, the final concentrations of $X-\alpha-G a l$ and AbA were $40 \mu \mathrm{g} / \mathrm{mL}$ and $200 \mathrm{ng} / \mathrm{mL}$, respectively. A comparison with the colonies transformed with pGBKT7 empty vector made it easy to distinguish if the bait plasmid had induced auto-activation and toxicity. $\mathrm{Y} 2 \mathrm{H}$ 
system was performed between recombinant pGBKT7-TaGAPCp1 (bait) and wheat cDNA library (prey) (Clontech). The bait strain was co-cultured with the library strain Y187 until the fertilized egg was examined under a microscope $(40 \times)$. To screen the cDNA library, the mated cells were coated on the 150-mm double dropout medium SD/-Leu/-Trp/X- $\alpha-\mathrm{Gal} / \mathrm{AbA}(\mathrm{DDO} / \mathrm{X} / \mathrm{A}$ ) and $\mathrm{SD} /$-Ade/-His/-Leu/-Trp/X- $\alpha$-Gal/AbA (QDO/X/A).

\subsection{Analysis of the Positive Preys}

When the interaction was confirmed as positive, the insert sequence of the prey plasmid was sequenced by the $\mathrm{T} 7$ sequencing primer. We ensured that the open reading frame (ORF) was fused in frame to the GAL4 transcriptional activation domain. The insert sequence of the positive preys was subjected to BLAST search (https:/ / blast.ncbi.nlm.nih.gov/Blast.cgi) to identify the corresponding Triticum aestivum genes.

\subsection{Identification of Prey Proteins Interacting with TaGAPCp1}

Prey proteins were subcloned into the pGADT7 prey vector. The interaction of preys with TaGAPCp1 was confirmed by co-transforming into Y2HGold Yeast Strain with the bait (TaGAPCp1 in pGBKT7) vector. In addition, the pGBKT7-p53 and pGBKT7-Lam bait plasmids were separately transformed into Y2HGold Yeast Strain with the prey plasmid (pGADT7-T) as positive and negative controls. Moreover, the interaction of Cyt b6f with TaGAPCp1 was also verified by BiFC method and the used primers were listed in Table S1. The transient assay was performed by protoplasts cells of tobacco leaves, and yellow fluorescent protein (YFP) fluorescence was observed with confocal laser scanning microscopy (LSM710, Karl Zeiss). YFP fluorescence signals were collected in the $500-570 \mathrm{~nm}$ wavelength range. For chloroplast autofluorescence, the wavelength range monitored was $630-700 \mathrm{~nm}[53,54]$.

\subsection{Identification and Sequence Analysis of Cyt $b 6 f$}

The physical and chemical properties of the protein were determined on the ProtParam (https:/ / web.expasy.org/protparam/). To analyze the Cyt b6f protein well, its expression under abiotic stresses was measured by qRT-PCR. In addition, to analyze the relationship between Cytb6f and TaGAPCp1, we measured the chlorophyll content of OE-TaGAPCp1 and wild type Arabidopsis, respectively (Acetone method).

\section{Conclusions}

In conclusion, our data suggested that TaGAPCp1 plays an important role in responding to drought stress by the ABA signaling pathway. At the same time, we revealed that $\mathrm{H}_{2} \mathrm{O}_{2}$ could be used as a signaling molecule in the process of $\mathrm{Cyt} b 6 \mathrm{f}$ response to abiotic stress. Since the interaction between Cyt b6f and TaGAPCp1 was confirmed, it was speculated that the stress resistance process of TaGAPCp1 might probably be completed by $\mathrm{H}_{2} \mathrm{O}_{2}$-mediated ABA signaling pathway with $\mathrm{H}_{2} \mathrm{O}_{2}$ acting as a signal molecule, while the antioxidant activity of carotenoids in Cyt b6f could probably maintain the relative balance of ROS. These findings reveal TaGAPCp1 is critical for abiotic stress responses in wheat.

Supplementary Materials: Supplementary materials can be found at http:/ /www.mdpi.com/1422-0067/20/5/ $1104 / s 1$.

Author Contributions: Conceptualization, X.L. and L.Z.; Data curation, F.L., L.Z. and X.D.; Funding acquisition, S.Y.; Investigation, X.L., W.W. and S.Y.; Methodology, W.W. and L.Z.; Project administration, S.Y.; Resources, S.Y.; Software, X.L., W.W. and F.L.; Supervision, Y.L. and S.Y.; Writing-original draft, X.L.; Writing一review and editing, X.L., F.L. and X.D.

Funding: This research was funded by The National Nature Science Foundation of China (No. 31671609). 
Acknowledgments: We acknowledge the teachers who gave us technical guidance during the experiment and the fellows who helped us in the research. Finally, we also acknowledge the countries and schools that gave us the platform for research.

Conflicts of Interest: The authors declare no conflict of interest.

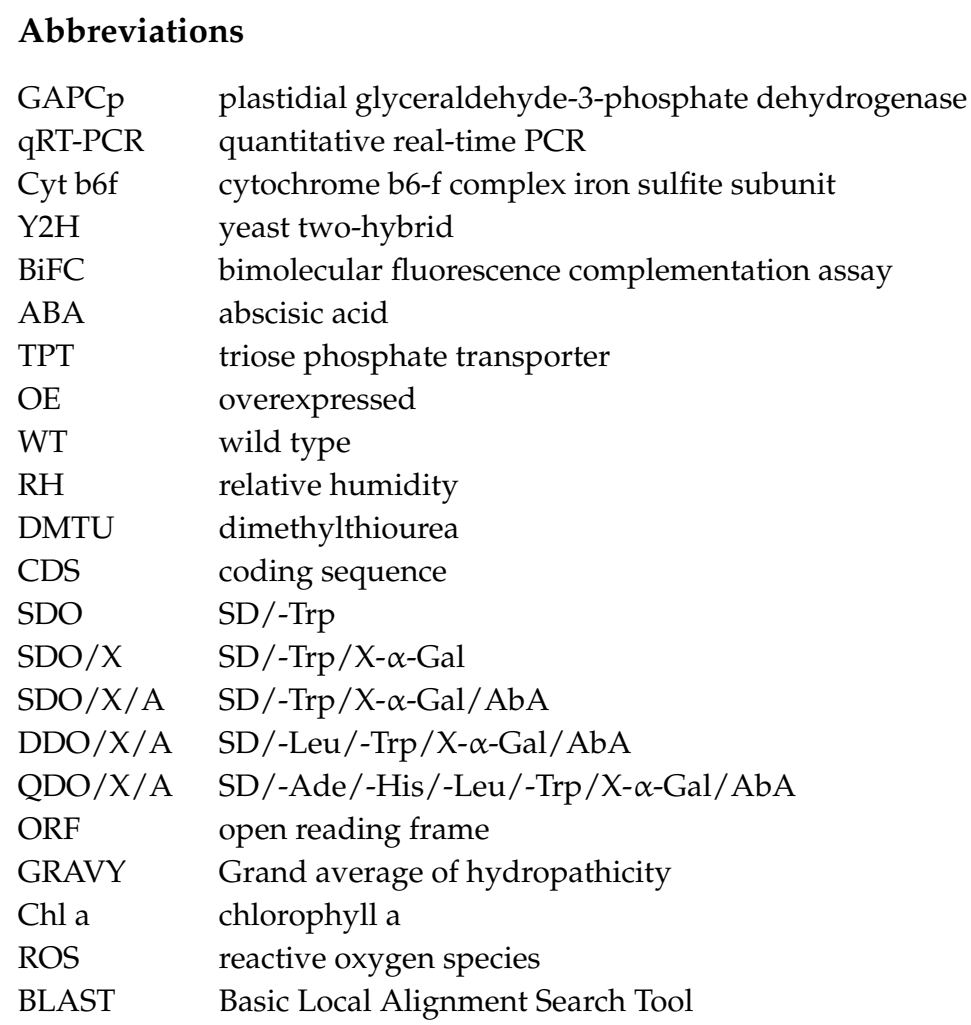

\section{References}

1. Nezhadahmad, A.; Prodhan, Z.H.; Faruq, G. Drought tolerance in wheat. Sci. World J. 2013, 3, 1-12. [CrossRef] [PubMed]

2. Shi-Bo, F.; Yue, Q.I.; Guo-Jun, H. Meteorological Drought Trend in Winter and Spring from 1961 to 2010 and Its Possible Impacts on Wheat in Wheat Planting Area of China. Sci. Agric. Sin. 2014, 47, 1754-1763.

3. Ma, S. On the functional diversity of glyceraldehyde-3-phosphate dehydrogenase: Biochemical mechanisms and regulatory control. Biochim. Biophys. Acta 2011, 1810, 741-751. [CrossRef]

4. Nicholls, C.; Li, H.; Liu, J.P. GAPDH: A common enzyme with uncommon functions. Clin. Exp. Pharmacol. Physiol. 2012, 39, 674-679. [CrossRef] [PubMed]

5. Jesús, M.B.; Borja, C.M.; Manuel, A. A critical role of plastidial glycolytic glyceraldehyde-3-phosphate dehydrogenase in the control of plant metabolism and development. Plant Signal. Behav. 2010, 5, 67. [CrossRef]

6. Jesús, M.B.; Borja, C.M.; Jose, M.M. Plastidial Glyceraldehyde-3-Phosphate Dehydrogenase Deficiency Leads to Altered Root Development and Affects the Sugar and Amino Acid Balance in Arabidopsis. Plant Physiol. 2009, 151, 541-558. [CrossRef]

7. Kim, J.W.; Dang, C.V. Multifaceted roles of glycolytic enzymes. Trends Biochem. Sci. 2005, 30, 142-150. [CrossRef] [PubMed]

8. MA, S. Subcellular dynamics of multifunctional protein regulation: Mechanisms of GAPDH intracellular translocation. Cell Biochem. 2012, 113, 2193-2200. [CrossRef]

9. Tristan, C.; Shahani, N.; Sedlak, T.W.; Sawa, A. The diverse functions of GAPDH: Views from different subcellular compartments Cell Signal. 2011, 23, 317-323. [CrossRef] [PubMed]

10. Cerff, R.; Chambers, S.E. Subunit structure of higher plant glyceraldehyde-3-phosphate dehydrogenases. Biol. Chem. 1979, 254, 6094-6098. 
11. Martin, W.; Cerff, R. Prokaryotic features of a nucleus-encoded enzyme. cDNA sequences for chloroplast and cytosolic glyceraldehyde-3-phosphate dehydrogenases from mustard (Sinapis alba). Eur. J. Biochem. 1986, 159, 323-331. [CrossRef] [PubMed]

12. Petersen, J.; Brinkmann, H.; Cerff, R. Origin, evolution, and metabolic role of a novel glycolytic GAPDH enzyme recruited by land plant plastids. Mol. Evol. 2003, 57, 16-26. [CrossRef] [PubMed]

13. Kwon, H.B.; Park, S.C.; Peng, H.P. Identification of a light-responsive region of the nuclear gene encoding the B subunit of chloroplast glyceraldehyde 3-phosphate dehydrogenase from Arabidopsis thaliana. Plant Physiol. 1994, 105, 357-367. [CrossRef] [PubMed]

14. Zeng, L.; Deng, R.; Guo, Z.; Yang, S.; Deng, X. Genome-wide identification and characterization of Glyceraldehyde-3-phosphate dehydrogenase genes family in wheat (Triticum aestivum). BMC Genom. 2016, 17, 240. [CrossRef] [PubMed]

15. Marri, L.; Pesaresi, A.; Valerio, C. In vitro characterization of Arabidopsis CP12 isoforms reveals common biochemical and molecular properties. J. Plant Physiol. 2010, 167, 939-950. [CrossRef] [PubMed]

16. Flores-Tornero, M.; Anoman, A.D.; Rosa-Tellez, S.; Toujani, W.; Weber, A.P.; Eisenhut, M.; Kurz, S.; Alseekh, S.; Fernie, A.R.; Munoz-Bertomeu, J.; Ros, R. Overexpression of the triose phosphate translocator (TPT) complements the abnormal metabolism and development of plastidial glycolytic glyceraldehyde-3-phosphate dehydrogenase mutants. Plant J. 2017, 89, 1146-1158. [CrossRef] [PubMed]

17. Zaffagnini, M.; Fermani, S.; Costa, A.; Lemaire, S.D.; Trost, P. Plant cytoplasmic GAPDH: Redox post-translational modifications and moonlighting properties. Front. Plant Sci. 2013, 4, 450. [CrossRef] [PubMed]

18. Anoman, A.D.; Flores-Tornero, M.; Rosa-Tellez, S.; Munoz-Bertomeu, J.; Segura, J.; Ros, R. The specific role of plastidial glycolysis in photosynthetic and heterotrophic cells under scrutiny through the study of glyceraldehyde-3-phosphate dehydrogenase. Plant Signal. Behav. 2016, 11. [CrossRef] [PubMed]

19. Anoman, A.D.; Munoz-Bertomeu, J.; Rosa-Tellez, S.; Flores-Tornero, M.; Serrano, R.; Bueso, E.; Fernie, A.R.; Segura, J.; Ros, R. Plastidial Glycolytic Glyceraldehyde-3-Phosphate Dehydrogenase Is an Important Determinant in the Carbon and Nitrogen Metabolism of Heterotrophic Cells in Arabidopsis. Plant Physiol. 2015, 169, 1619-1637. [CrossRef] [PubMed]

20. Muñozbertomeu, J.; Bermúdez, M.A.; Segura, J. Arabidopsis plants deficient in plastidial glyceraldehyde-3-phosphate dehydrogenase show alterations in abscisic acid (ABA) signal transduction: Interaction between ABA and primary metabolism. J. Exp. Bot. 2010, 62, 1229-1239. [CrossRef] [PubMed]

21. Winter, D.; Vinegar, B.; Nahal, H. An "Electronic Fluorescent Pictograph" Browser for Exploring and Analyzing Large-Scale Biological Data Sets. PLoS ONE 2007, 2, e718. [CrossRef] [PubMed]

22. Fields, S.; Song, O. A novel genetic system to detect protein-protein interactions. Nature 1989, 340, $245-246$. [CrossRef] [PubMed]

23. Whitelegge, J.P.; Zhang, H.M.; Aguilera, R.; Taylor, R.M.; Cramer, W.A. Full subunit coverage liquid chromatography electrospray ionization mass spectrometry (LCMS+) of an oligomeric membrane protein: Cytochrome b(6)f complex from spinach and the cyanobacterium Mastigocladus laminosus. Mol. Cell. Proteom. 2002, 1, 816-827. [CrossRef]

24. Kurisu, G.; Zhang, H.M.; Smith, J.L.; Cramer, W.A. Structure of the cytochrome b6f complex of oxygenic photosynthesis: Tuning the cavity. Science 2003, 302, 1009-1014. [CrossRef] [PubMed]

25. Stroebel, D.; Choquet, Y.; Popot, J.L.; Picot, D. An atypical haem in the cytochrome b6f complex. Nature 2003, 426, 413-418. [CrossRef] [PubMed]

26. Toujani, W. Functional Characterization of the Plastidial 3-Phosphoglycerate Dehydrogenase Family in Arabidopsis. Plant Physiol. 2013, 163, 1164-1178. [CrossRef] [PubMed]

27. Jia, Y.; Li, S.; Allen, G.; Feng, S.; Xue, L. A novel glyceraldehyde-3-phosphate dehydrogenase (GAPDH) promoter for expressing transgenes in the halotolerant alga Dunaliella salina. Curr. Microbiol. 2012, 64, 506-513. [CrossRef]

28. Voet, D.J.; Voet, J.G. Biochemistry; Wiley, J: New York, NY, USA, 2011; Volume 978, pp. 57091-57095.

29. Alattala, M.N.; Wang, X.; Abouattia, M.A. A novel TaMYB4 transcription factor involved in the defence response against Puccinia striformis f. sp. tritici and abiotic stresses. Plant Mol. Biol. 2014, 84, 589. [CrossRef] [PubMed]

30. Suh, J.Y.; Kim, S.J. Arabidopsis Toxicos en Levadura 78 (AtATL78) mediates ABA-dependent ROS signaling in response to drought stress. Biochem. Biophys. Res. Commun. 2016, 469, 8-14. [CrossRef] [PubMed] 
31. Cramer, W.A.; Yamashita, E.; Baniulis, D. Structure-Function of the Cytochrome b6f Complex of Oxygenic Photosynthesis. Encycl. Biol. Chem. 2013, 84, 329-334. [CrossRef]

32. Wang, Y.; Xu, C.; Zhang, B. Physiological and proteomic analysis of rice (Oryza sativa L.) in flag leaf during flowering stage and milk stage under drought stress. Plant Growth Regul. 2017, 82, 1-18. [CrossRef]

33. Zhou, S.; Li, M.; Guan, Q.; Liu, F.; Zhang, S.; Chen, W.; Yin, L.; Qin, Y.; Ma, F. Physiological and proteome analysis suggest critical roles for the photosynthetic system for high water-use efficiency under drought stress in Malus. Plant Sci. 2015, 236, 44-60. [CrossRef] [PubMed]

34. Liu, P.; Xu, Z.S.; Lu, P.P.; Hu, D.; Chen, M.; Li, L.C.; Ma, Y.Z. A wheat PI4K gene whose product possesses threonine autophophorylation activity confers tolerance to drought and salt in Arabidopsis. Exp. Bot. 2013, 64, 2915-2927. [CrossRef] [PubMed]

35. Sunil, B.; Saini, D.; Bapatla, R.B. Photorespiration is complemented by cyclic electron flow and the alternative oxidase pathway to optimize photosynthesis and protect against abiotic stress. Photosynthesis Res. 2018, 1-13. [CrossRef] [PubMed]

36. Wang, H.; Huang, J.; Liang, X.; Bi, Y. Involvement of hydrogen peroxide, calcium, and ethylene in the induction of the alternative pathway in chillingstressed Arabidopsis callus. Planta 2012, 235, 53-67. [CrossRef] [PubMed]

37. Esteban, R.; Moran, J.F.; Becerril, J.M.; García-Plazaola, J.I. Versatility of carotenoids: An integrated view on diversity, evolution, functional roles and environmental interactions. Environ. Exp. Bot. 2015, 119, 63-75. [CrossRef]

38. Kim, S.H.; Ahn, Y.O.; Ahn, M.J.; Jeong, J.C.; Lee, H.S.; Kwak, S.S. Cloning and characterization of an Orange gene that increases carotenoid accumulation and salt stress tolerance in transgenic sweetpotato cultures. Plant Physiol. Biochem. 2013, 70, 445-454. [CrossRef] [PubMed]

39. Kim, H.S.; Ji, C.Y.; Lee, C.J.; Kim, S.E.; Park, S.C.; Kwak, S.S. Orange: A target gene for regulating carotenoid homeostasis and increasing plant tolerance to environmental stress in marginal lands. J. Exp. Bot. 2018, 69, 3393-3400. [CrossRef] [PubMed]

40. Brunetti, C.; Guidi, L.; Sebastiani, F.; Tattini, M. Isoprenoids and phenylpropanoids are key components of the antioxidant defense system of plants facing severe excess light stress. Environ. Exp. Bot. 2015, 119, 54-62. [CrossRef]

41. Jiang, M. Effect of Abscisic Acid on Active Oxygen Species, Antioxidative Defence System and Oxidative Damage in Leaves of Maize Seedlings. Plant Cell Physiol. 2001, 42, 1265-1273. [CrossRef] [PubMed]

42. Kwak, J.M.; Mori, I.C.; Pei, Z.M.; Leonhardt, N.; Torres, M.A.; Dangl, J.L.; Bloom, R.E.; Bodde, S.; Jones, J.D.; Schroeder, J.I. NADPH oxidase Atrbohd and Atrbohf genes function in ROS-dependent ABA signaling in Arabidopsis. EMBO J. 2003, 22, 2623-2633. [CrossRef] [PubMed]

43. Suhita, D.; Raghavendra, A.S.; Kwak, J.M.; Vavasseur, A. Cytoplasmic alkalization precedes reactive oxygen species production during methyl jasmonate- and abscisic acid-induced stomatal closure. Plant Physiol. 2004, 134, 1536-1545. [CrossRef] [PubMed]

44. Cai, S.; Chen, G.; Wang, Y. Evolutionary Conservation of ABA Signaling for Stomatal Closure in Ferns. Plant Physiol. 2017, 174, 732-747. [CrossRef] [PubMed]

45. Nobuhiro, S.; Kazuma, K. Coordination Between ROS Regulatory Systems and Other Pathways Under Heat Stress and Pathogen Attack. Front. Plant Sci. 2018, 9, 490.

46. Bright, J.; Desikan, R.; Hancock, J.T.; Weir, I.S.; Neill, S.J. ABAinduced NO generation and stomatal closure in Arabidopsis are dependent on $\mathrm{H}_{2} \mathrm{O}_{2}$ synthesis. Plant J. 2006, 45, 113-122. [CrossRef] [PubMed]

47. Li, J.J.; Li, Y.; Yin, Z.G.; Jiang, J.H.; Zhang, M.H.; Guo, X.; Ye, Z.J. OsASR5 enhances drought tolerance through a stomatal closure pathway associated with $\mathrm{ABA}$ and $\mathrm{H}_{2} \mathrm{O}_{2}$ signalling in rice. Plant Biotechnol. J. 2017, 15, 183-196. [CrossRef] [PubMed]

48. Kenneth, J.L.; Thomas, D.S. Analysis of Relative Gene Expression Data Using Real-Time Quantitative PCR and the $2^{-\Delta \Delta C T}$, Method. Methods A Comp. Methods Enzymol. 2001, 25, 402-408. [CrossRef]

49. Seo, D.H.; Ryu, M.Y.; Ammes, F. Roles of Four Arabidopsis U-Box E3 Ubiquitin Ligases in Negative Regulation of Abscisic Acid-Mediated Drought Stress Responses. Plant Physiol. 2012, 160, 556-568. [CrossRef] [PubMed]

50. Ryu, M.Y.; Cho, S.K.; Kim, W.T. The Arabidopsis C3H2C3-Type RING E3 Ubiquitin Ligase AtAIRP1 Is a Positive Regulator of an Abscisic Acid-Dependent Response to Drought Stress. Plant Physiol. 2010, 154, 1983-1997. [CrossRef] [PubMed] 
51. Sheen, J. Signal transduction in maize and Arabidopsis mesophyll protoplasts. Plant Physiol. 2001, 127, 1466-1475. [CrossRef] [PubMed]

52. Yu, C.; Wang, L.; Chen, C. Protoplast: A more efficient system to study nucleo-cytoplasmic interactions. Biochem. Biophys. Res. Commun. 2014, 450, 1575-1580. [CrossRef] [PubMed]

53. Liu, J.; Wang, X.; Hu, Y.; Hu, W.; Bi, Y. Glucose-6-phosphate dehydrogenase plays a pivotal role in tolerance to drought stress in soybean roots. Plant Cell Rep. 2013, 32. [CrossRef] [PubMed]

54. Oh, M.H.; Wang, X.F.; Kota, U.; Goshe, M.B.; Clouse, S.D.; Huber, S.C. Tyrosine phosphorylation of the BRI1 receptor kinase emerges as a component of brassinosteroid signaling in Arabidopsis. Proc. Natl. Acad. Sci. USA 2009, 106, 658-663. [CrossRef] [PubMed]

(C) 2019 by the authors. Licensee MDPI, Basel, Switzerland. This article is an open access article distributed under the terms and conditions of the Creative Commons Attribution (CC BY) license (http:/ / creativecommons.org/licenses/by/4.0/). 